\title{
Morphostructural Characterization of Hassall's Corpuscles in Lamb
}

\author{
Vasile RUS ${ }^{1}$, Adrian GAL ${ }^{1}$, Flavia RUXANDA ${ }^{1}$, Bianca BOȘCA ${ }^{2}$, George NADĂȘ ${ }^{1}$, Cristian RAȚIU ${ }^{3}$, Viorel \\ MICLĂUȘ ${ }^{1 *}$
}

${ }^{1}$ University of Agricultural Sciences and Veterinarian Medicine, Cluj-Napoca, Romania

2 "Iuliu Haţieganu" University of Medicine and Pharmacy, Cluj-Napoca, Romania

${ }^{3}$ University of Oradea, Faculty of Medicine and Pharmacy, Oradea, Romania

* Corresponding author e-mail:vmiclaus@usamvcluj.ro

Bulletin UASVM Veterinary Medicine 71(2) / 2014,

Print ISSN 1843-5270; Electronic ISSN 1843-5378

DOI:10.15835/buasvmcn-vm: 10523

\begin{abstract}
The aim of this study is to assess Hassall's corpuscles in lamb. Thymus samples were harvested from 10 lambs ( 3 months old) and histologically processed. From the harvested samples, $5 \mu \mathrm{m}$ seriated sections were made, stained with Goldner's trichrome method and examined under light microscope. In the medulla of the thymic lobules there are on average 7-8 highly polymorphic Hassall's corpuscles. The majority of the corpuscles $(80 \%)$ have a diameter between 5 and $50 \mu \mathrm{m}, 15 \%$ between 50 and $100 \mu \mathrm{m}$ and only $5 \%$ have a diameter of over $100 \mu \mathrm{m}$. Only $20-25 \%$ among them have a typical „onion-like” structure, $40-45 \%$ present different keratinization degrees and $3-5 \%$ are cavitary corpuscles, containing degenerated cell fragments. Hassall's corpuscles in lamb are numerous and highly polymorphic.
\end{abstract}

Keywords: Hassall's corpuscle, lamb, polymorphism

\section{INTRODUCTION}

Hassall's corpuscles, described for the first time by Hassall (1846), are specific structures, very polymorph (Rotaru, 1977), present in the medulla of the thymic lobule. After some authors, the size of Hassall's corpuscles ranges between 10 and $1000 \mu \mathrm{m}$ (Bodey,1977; Bodey and Hadjioloff, 1977), while others report sizes between 20 and $150 \mu \mathrm{m}$ (Izard, 1965; Rotaru, 1977). Ever since the first description, Hassall's corpuscles were the subject of many research in different animal species (Kohnen and Weiss, 1964; Cesarini et al., 1968; Cabanie and Mirouze, 1971; Chapman and Allen, 1971; Pfoch, 1971; Frazier, 1973; Miclăuș et al., 2009). Aspects related to their structure and function were studied. Hassall's corpuscles are relatively scarce and small in rats (Harland, 1940) and mice (Clark, 1963), whereas in bovine (Rotaru, 1977), nutria (Miclăuș et al., 2009) and guinea pig (Kohnen and Weiss, 1964) they are larger and more numerous. Although various studies have been made, nowadays, there are still a lot of questions, especially concerning the role of this specific structures present in the medulla of the thymic lobules. In this context, we considered it opportune to conduct investigations regarding the frequency and polymorphism of these structures in lamb.

\section{MATERIAL AND METHODS}

Thymus samples were harvested from 10 clinically healthy, 3 months old lambs, (5 males and 5 females, hybrid merino, sacrificed for own consumption by private breeders from BistrițaNăsăud couty) and fixed in Stieve's solution, dehydrated in ethanol, clarified in butanol and embedded in paraffin. We made seriated sections with a $5 \mu \mathrm{m}$ thickness from each paraffin block and then stained them with Goldner's trichrome method. 5 slides (every 10th slide from each animal) were examined under light microscope (Olympus BX41, equipped with Olympus E 330 
camera). The Hassall corpuscles present on the section surface were counted and pictures were taken. We measured the diameter of the corpuscles in these images using Adobe Photoshop CS 2 program, 9.0 version. In order to calibrate the measurements, we used a blade micrometer and the statistical analysis was made using Microsoft Excel (2003).

\section{RESULTS AND DISCUSSION}

Hassall's corpuscles were identified in the medulla of the thymic lobules in large numbers. In each lobule there are on average 7-8 Hassall's corpuscles. Their size varies between wide limits. The majority of the identified corpuscles (approximately 80\%) have a diameter between 5 and $50 \mu \mathrm{m}, 15 \%$ between $50-100 \mu \mathrm{m}$, and $5 \%$ over $100 \mu \mathrm{m}$. Generally, the majority of the corpuscles have small sizes in the incipient stages of organization and are formed out of a small number of epithelioreticular cells in various stages of degeneration. The great majority of these cells are in incipient stages of degeneration, some in advanced stages and sometimes, some cells present incipient signs of keratinization (Fig. 1).
In the case of Hassall's corpuscles of medium sizes, at most $20-25 \%$ among them are round or oval and have a typical "onion-like” structure (Fig. 2), $25-30 \%$ have other shapes (Fig. 3) and $45-55 \%$ among them are compound corpuscles, resulted after merging of the neighbouring corpuscles. Cells forming the medium Hassall's cospuscles present advanced signs of degeneration and in approximately $60 \%$ among them, the epithelioreticular cells are keratinized. Only a few of the medium sized corpuscles (3-5\%) are cavitary.

There are also large corpuscles and 95\% among them are compound corpuscles, resulted after merging of 2 or more neighbouring corpuscles (Fig. 4) and approximately 50\% among them are keratinized (Fig. 5). A relatively small number (5-10\%) among the corpuscles are cavitary and contain cell fragments in advanced stages of degeneration (Fig. 6).

It's worth noting that in the structure of large sized corpuscles there are both cells that present incipient signs of degeneration and cells in advanced or very advanced stanges of degeneration. Microscopical examination highlighted that in lamb, Hassall's corpuscles

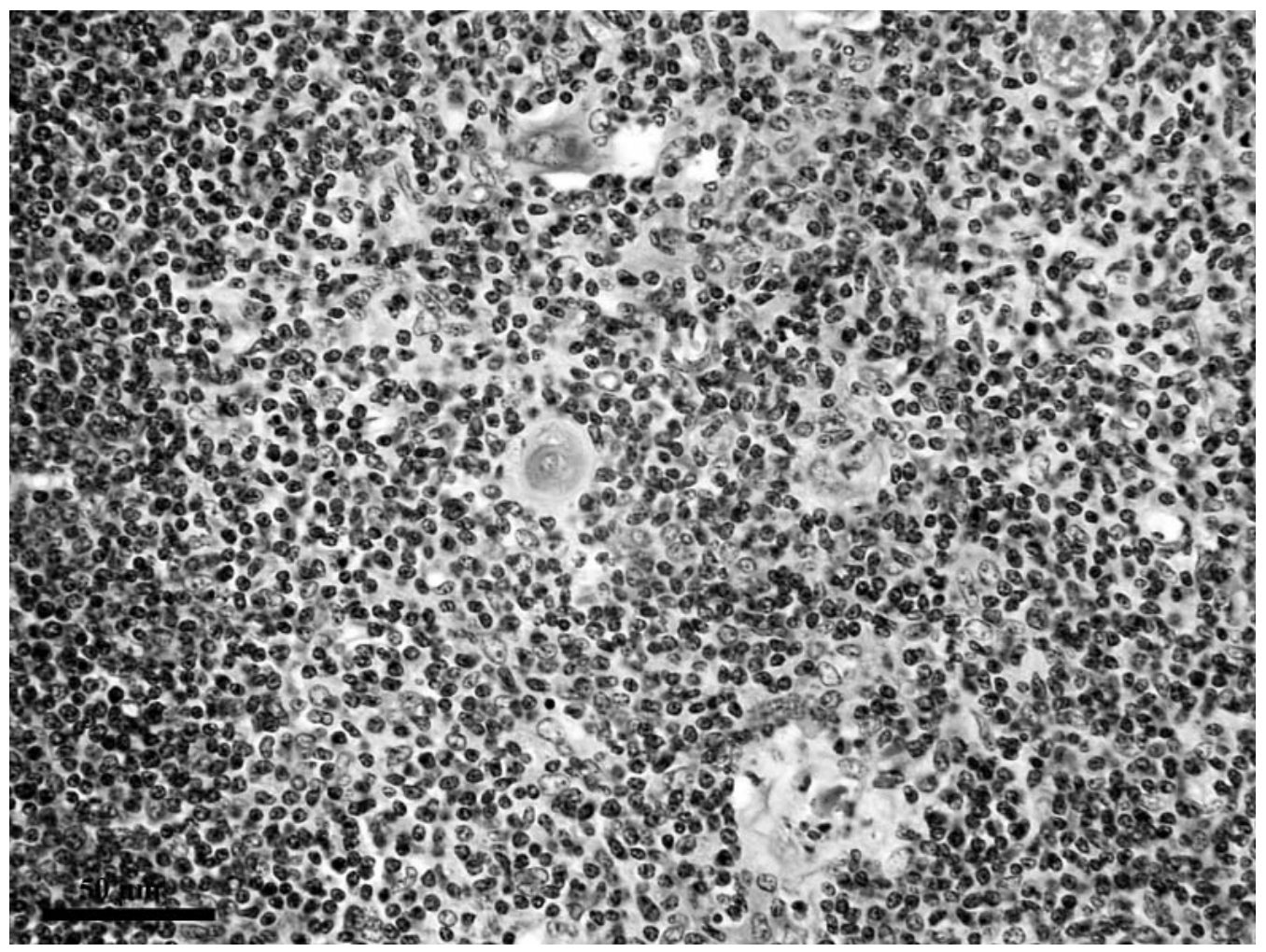

Fig. 1. Small Hassall's corpuscles (Goldner's Trichrome stain) 


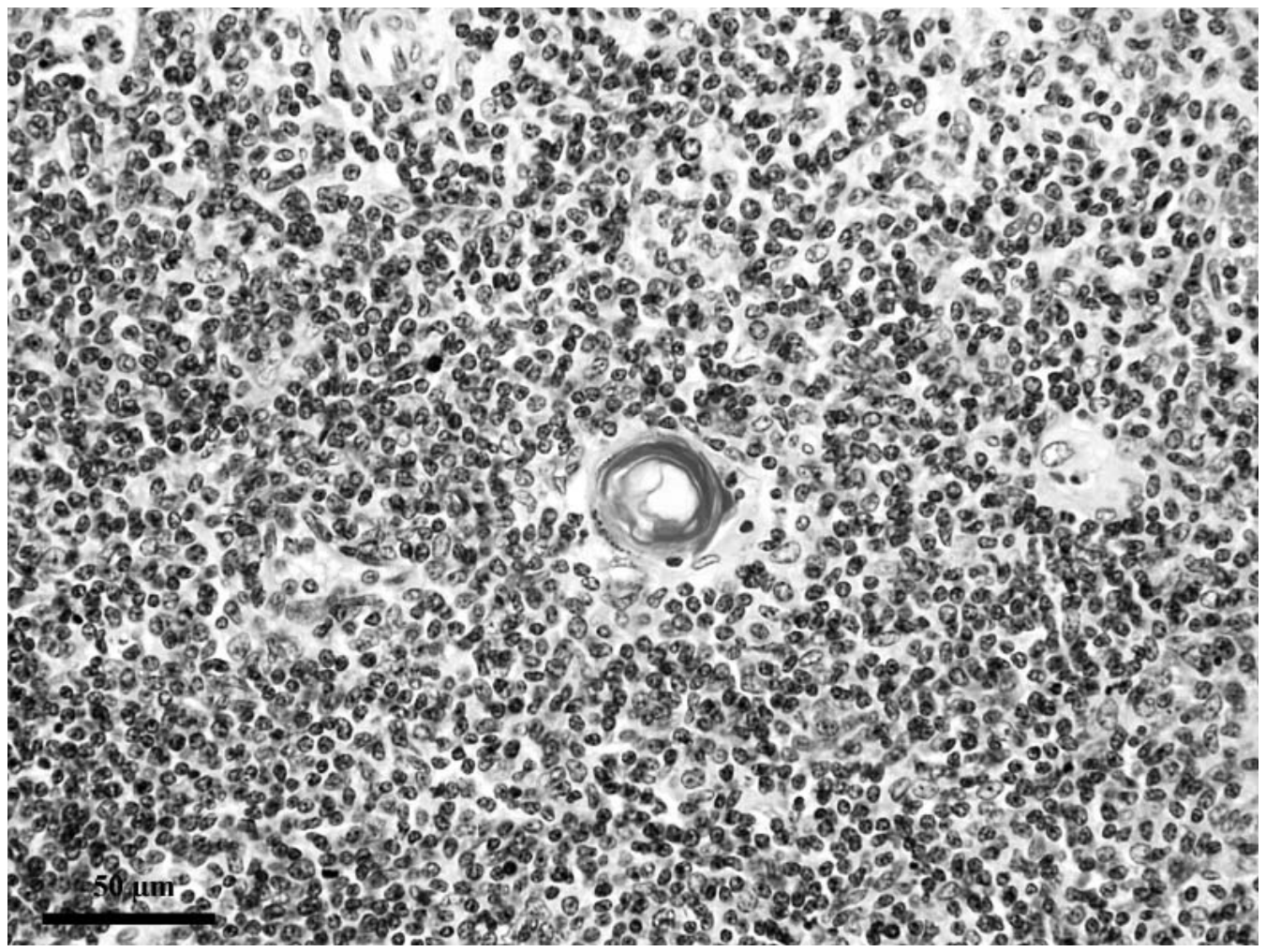

Fig. 2. Hassall's corpuscle with a typical aspect (Goldner's Trichrome stain)

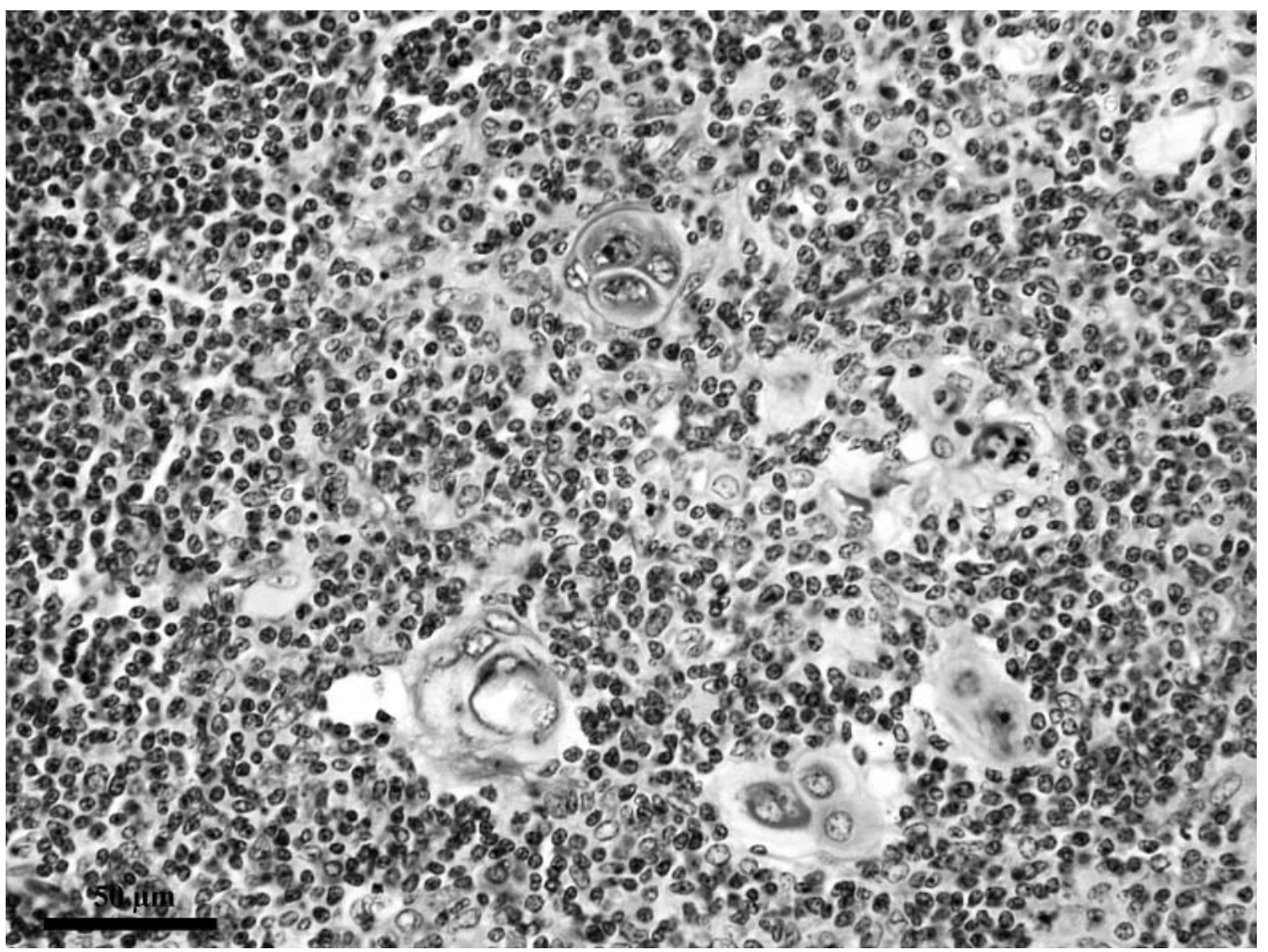

Fig. 3. Polymorph Hassall's corpuscles (Goldner's Trichrome stain) 


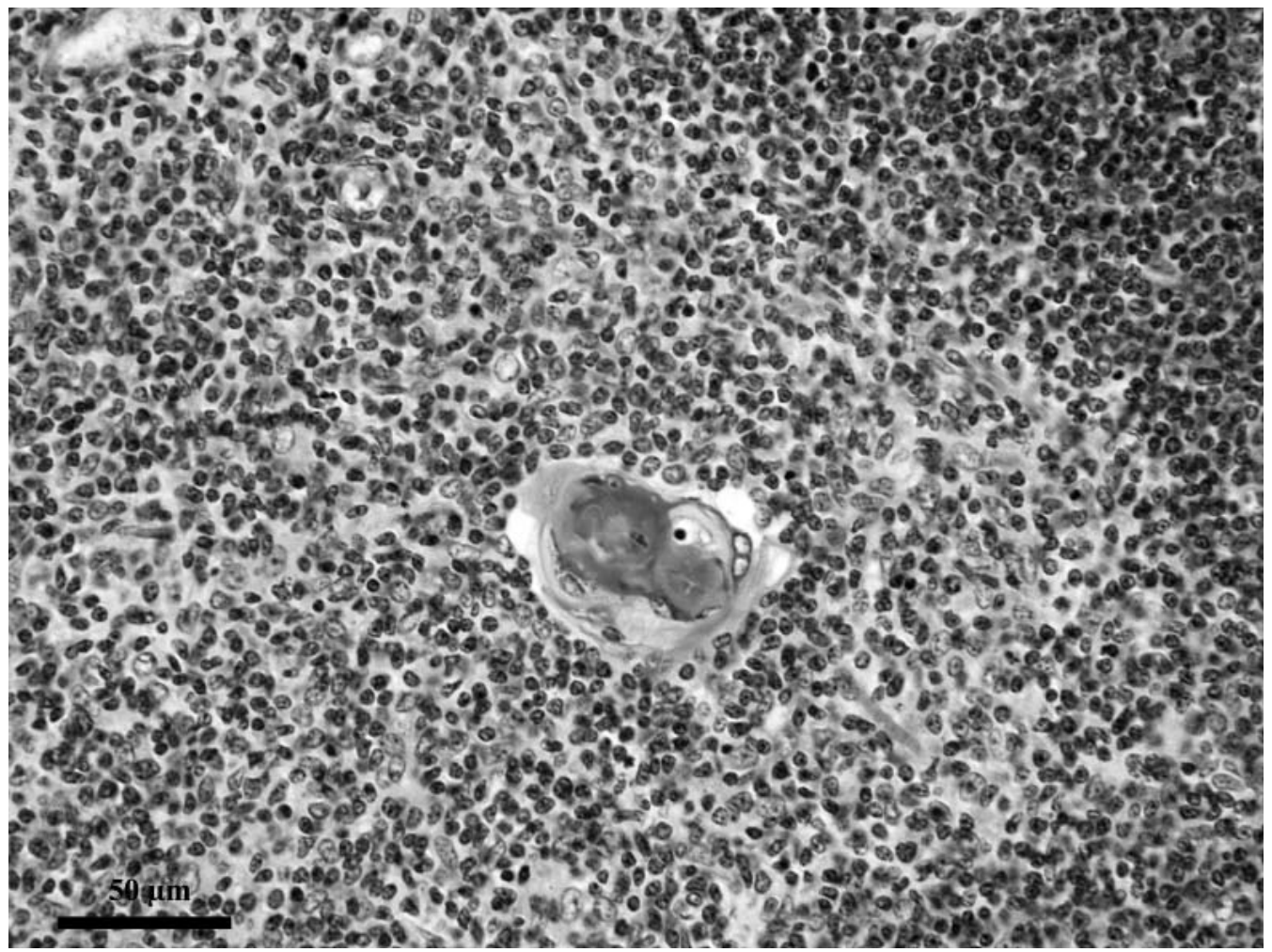

Fig. 4. Compound Hassall's corpuscle (Goldner's Trichrome stain)

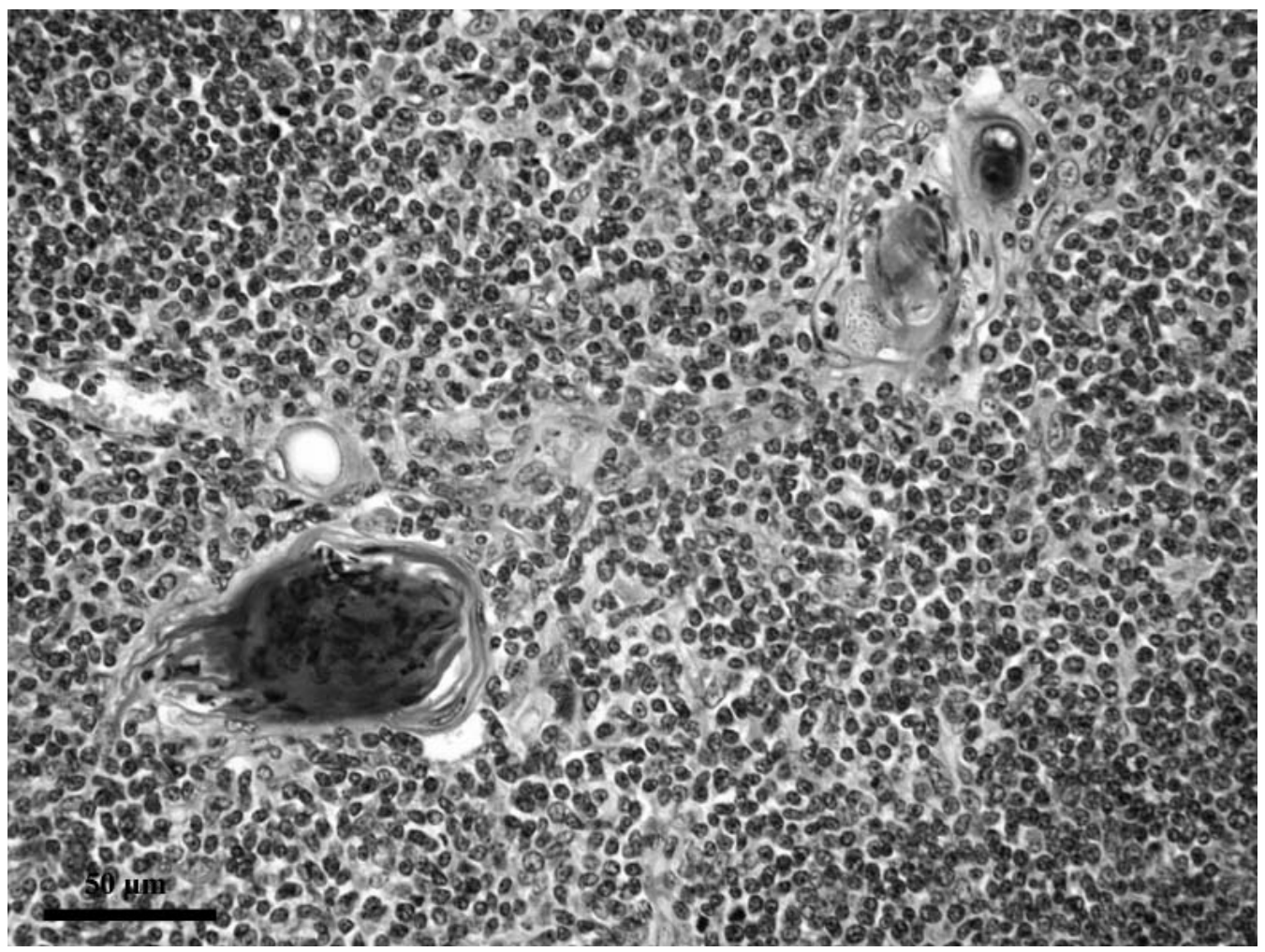

Fig. 5. Keratinized Hassall's corpuscles (Goldner's Trichrome stain) 


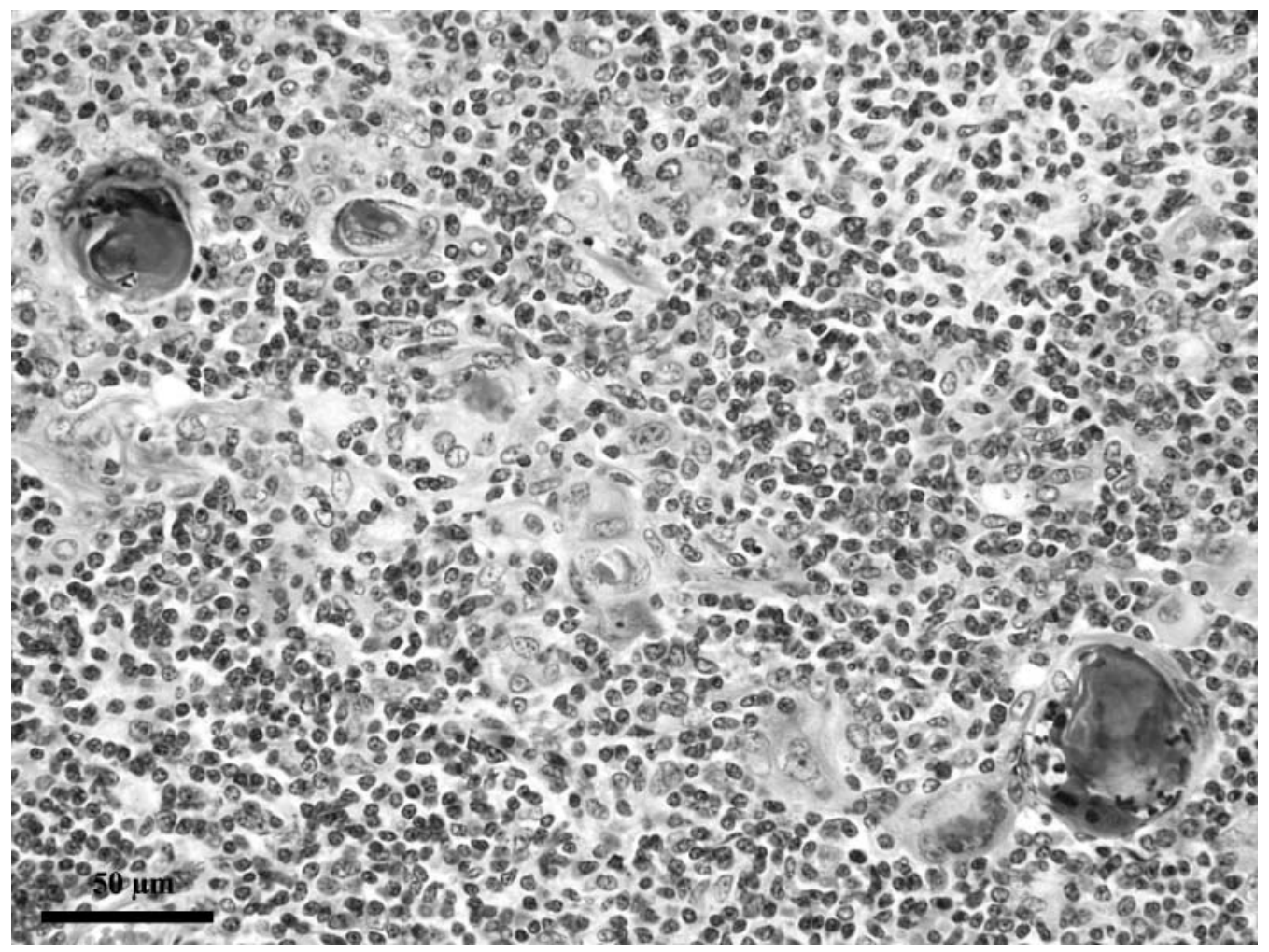

Fig. 6. Cavitary Hassall's corpuscles with cellular debris (Goldner's Trichrome stain)

are relatively numerous, with relatively large differences from one lobule to another. Thus, there is a small number of lobules in which there are no corpuscles on the section surface, others contain 2-3 corpuscles, but there are also lobules in which they are numerous (up to 15-16 corpuscles/ lobule).

The number of Hassall's corpuscles in lamb is comparable with the one described in bovines (Rotaru, 1977; Miclăuș et al., 1997), humans (Raica et al., 2006) and guinea pigs (Kohnen şi Weiss, 1964), is less numerous than the one in nutria (Miclăuș et al., 2009) and far numerous than the one in mice (Clark, 1963; Kohnen and Weiss, 1964) and rat (Harlam, 1940; Pfoch, 1971). Furthermore, the polymorphism and keratinization degree of Hassall's corpuscles in lamb is comparable to the one described in bovines (Rotaru, 1977), a lot more keratinized and polymorph than the ones present in the medulla of thymic lobules in rat and mouse (Harlam, 1940; Clark, 1963; Kohnen and Weiss, 1964; Pfoch, 1971), but less polymorph and keratinized than the ones described in nutria (Miclăuș et al., 2009).

\section{CONCLUSIONS}

Lamb thymus displays a relatively large number of Hassall corpuscles, on average 7-8 corpuscles in each lobule, but with relatively large differences frome one lobule to another.

They are very polymorph regarding their shape, from approximately round with a typical "onion-like" structure aspect, to elongated, branched and even strange shapes.

Hassall's corpuscles in lamb are also very polymorph in size. There are small corpuscles in incipient stages of development, to macrocorpuscles resulted from merging of some neighbouring corpuscles.

\section{REFERENCES}

1. Bodey B, Hadjioloff AI. (1977). Thymus development, structure and function. Nature (Bulgaria) 26: 11-19.

2. Bodey B. (1977). Histomorphology and histochemistry of the human thymus during its prenatal ontogenesis. Dissertation, Inst Morphol, Bulg Acad Sci, Sofia, Bulgaria, pp 1-360.

3. Cabanie, P., Mirouze, P. (1971). Observations ultrastructurales de thymus de chat a differents ages, Rev. Med. Vet., 122: 639-652. 
4. Cesarini, J.P., Benkoel, L., Bonneau, H. (1968). Ultrastructure comparee du thymus chez la hamster jeune et adulte, C.R. Soc. Biol. (Paris), 162: 1975-1979.

5. Chapman, W.L., Allen, J.R. (1971). The Fine Structure of the Thymus of the Fetal and Neonatal Monkey (Macaca mulatta), Z. Zellforschung, 114: 220-233.

6. Clark, S. L, Jr. (1963). The thymus in mice of strain 129/J studied with electron microscope. Am. J. Anat.,112:1-34

7. Frazier, J.A. (1973). Ultrastructure of the chick Thymus, Z Zellforschung, 136: 191-205.

8. Harland, M. (1940). Early histogenesis of the thymus in the white rat. Anat. Rec., 77:247-271.

9. Hassall, A.H., 1846. The Microscopic Anatomy of the Human Body in Health and Disease. London.

10. Izard, I. (1965). Ultrastrucure des corpuscles de Hassall au cours de l'involution experimentale du thymus provoquee par la Folliculine, Z. Zellforschung, 66 :276-292.

11. Kohnen P. and L.Weiss, (1964). An Electron Microscopic Study of thymic Corpuscules in the Guinea Pig and the Mouse, Anat. Rec., 148: 29-57.
12. Miclăus V., Petrescu-Mag I. V., Rus V., Cadar D., Oana L., Ober C., (2009). Frequency and polymorphism of Hassall's corpuscles in normal thymus of nutria (Myocastor coypus). AACL Bioflux 2(2):121-131.

13. Miclăuş, V., Dana Pusta, O.Rotaru, Dana Pușcașiu, M.Mihaiu, (1997). Histological study concerning the thymus age involution in cattle, Bul. U.S.A.M.V.- Z.M.V., 51, 75-78.

14. Pfoch, M. (1971). Vergleichende elecktronenmikroskopische Untersuchung an entodermalen thymus. Retikulumzellen neugeborener und alter Wistar-Ratten, Z.Zellforschung., 114: 271-280.

15. Raica M., Encica Svetlana, Motoc A., Cimpean Aca Maria, Scridon T., Barsan M (2006). Structural heterogenity and immunohistochemical profile of Hassall corpuscles in normal human thymus. Ann Anat 188:345-352.

16. Rotaru, O. (1977). Aspecte morfologice normale şi patologice ale timusului la bovine, Teza de doctorat, F.M.V. Cluj-Napoca. 